\title{
Teacher training through social networking platforms: A case study on Facebook
}

\author{
Yasemin Demiraslan Çevik \\ Hacettepe University, Turkey \\ Serkan Çelik \\ Hacettepe University, Turkey \\ Tülin Haşlaman \\ Hacettepe University, Turkey
}

\begin{abstract}
Numerous studies have attempted to explain the role of social networking platforms within educational environments, though none of them has reported on their potential for enhancing professional development in education. The purpose of this qualitative research was to explore the reflections of prospective teachers who were assigned to design and conduct instruction on Facebook. Seven groups of prospective teachers $(n=25)$ attending a teacher training program in Turkey participated in the study. Reflections of these prospective teachers on online teaching through Facebook were elicited by means of reflective papers. As an outstanding result of the online teaching project in the current study, the prospective teachers gained positive experiences in utilising Facebook for designing and implementing online teaching activities that are in accordance with the constructivist learning paradigm. However, sustaining learner involvement, enhancing interaction, and problems resulting from group work processes were observed as destructive issues throughout the online teaching project.
\end{abstract}

\section{Introduction}

Social Networking Sites have attracted considerable attention from educators for what they believe to be significant potential for enhancing student learning. In particular, Facebook provides users with the most flexibility to connect with long-lost friends, post updated information about oneself including photos, and even share news and articles (Alloway \& Alloway, 2012; McCarthy, 2009). As the most preferred social networking platform, Facebook has received significant research interest from academics in various fields, which has led to the emergence of a growing body of literature on Facebook and its impacts on human life. Bosch (2009) defined general research on Facebook in the following four categories: social networking and social capital, identity construction, concerns with privacy, and the potential use of Facebook for academic purposes. However, there is little research on the academic uses of Facebook except for those focusing more on its social uses. Hew (2011) outlined the major topics of research on the pedagogical aspect of Facebook in three themes: students' usage profile or extent of use, the effects of Facebook use on learning, and students' attitudes towards Facebook. Existing literature presents contrasting views in relation to the educational value of Facebook. Some scholars suggest that students mostly use Facebook for socialisation purposes; thus the idea of using Facebook for educational purposes should be abandoned (Madge, Meek, Wellens, \& Hooley, 2009; Selwyn, 2009; Wise, Skues, \& Williams, 2011), whereas others argue for the potential benefits of Facebook to enhance student learning (Alloway \& Alloway, 2012; Greenhow, 2011; Yu, Tian, Vogel, \& Kwok, 2010).

As underlined by Manca and Ranieri (2013), who claim such discrepancies to be just theoretical, there is little empirical evidence supporting the effectiveness of Facebook as a learning environment. Despite the few studies that have investigated learners' attitudes towards incorporating social networking in class (Lin, Hou, Wang, \& Chang, 2013), to the best of our knowledge, no attention has been paid to the instructional experiences of prospective teachers' involvement in online teaching using social networking platforms. Exploitation of Facebook for teacher training purposes is very promising due to its inevitable presence in the would-be teachers' future professional environments and their prospective students' daily lives. Thus, for prospective teachers Facebook may serve as a platform where they can have pre-service experiences of designing and implementing online teaching activities compatible with up-to-date teaching paradigms. 
The current study focuses on how prospective teachers perceive the use of a leading social networking site (Facebook) for instructional purposes and how they integrate it into their online teaching. In the following sections, we first present the existing literature on the educational use of Facebook. Next, we report the results of the current study in which we attempted to identify the pedagogical potential of Facebook from the perspectives of teacher candidates.

\section{Theoretical background}

There is considerable optimism by many educators for the educational potential of Facebook, which is extensively used by students in their daily lives. Some features of Facebook are attributed to be pedagogically useful features that support student collaboration, student-generated content, studentstudent communication, and the personalisation and socialisation of student work (Dalsgaard, 2008; Pempek, Yermolayeva, \& Calvert, 2009). Postulations on the pedagogical potentials of Facebook embody the idea that "it encourages students to engage in creative and social learning processes" (Wiberg, 2007, p. 10) and allows them to utilise wide and diverse sources of information and opportunities for communication (Huijser, 2008). The relevant literature lists the capabilities of Facebook for teachers as well. It helps to enhance the credibility of teachers engaged in contemporary student culture (Kabilan, Ahmad, \& Abidin, 2010; Rutherford, 2009), to provide constructive educational outcomes in a variety of fields (Pempek et al., 2009), to practise a differential pedagogy (Hew, 2011), and to facilitate mentoring and interaction in the form of web-based communication (Hewitt \& Forte, 2006; Schwartz, 2009). Although instructors can utilise Facebook to connect with their pupils about assignments, upcoming events, deadlines, useful links, and educational materials, Facebook can also help students to get in touch with classmates regarding group work activities and collaborative class assignments ( $\mathrm{Yu}$ et al., 2010). Such advantages of Facebook may be utilised to overcome the interaction and social networking pitfalls of traditional distance education systems, because students will be more likely to participate in the learning environment if it is hosted by a site that is already deeply integrated into their day-to-day practices (Manca \& Ranieri, 2013; McCarthy, 2009).

Nevertheless, studies examining student behaviours in Facebook-based learning environments present mixed results regarding the effectiveness of Facebook as a formal instructional tool. On the one hand, a number of studies have noted a significant increase in students' active participation in the course when delivered on Facebook (DiVall \& Kirvin, 2012; Estus, 2010; Heiberger \& Harper, 2008). In a four-year longitudinal study, McCarthy (2013) examined the effect of a Facebook learning environment on firstyear design students' academic performance and engagement. The results show that Facebook facilitated interaction between a wide range of local and international peers, which then led to an increase in students' academic performance and course participation. Additionally, the author reported significant increases in the development of academic and social relationships between the students over the four-year period. Undoubtedly, these findings are both valuable and promising in terms of the long-term educational effects of using Facebook.

On the other hand, there are also studies that have found that the instructional use of Facebook is not positively correlated with learner engagement. For example, a study by Kop, Fournier and Mak (2011) showed that only a limited number of students were active in Facebook, while many were unwilling to use it due to privacy and security issues. Selwyn (2009) found that students occasionally exchanged academic information on Facebook, and when they did they mainly shared information on assessment requirements and course readings rather than engaging in elaborate discussions on course tasks and readings. Similar findings were confirmed by another study (English \& Duncan-Howell, 2008), the results of which indicate that the majority of content that students shared on Facebook was related to affective subjects, while only a small number of posts were education related. English and DuncanHowell's (2008) study implies that students tend to use Facebook to support their social relationships rather than discussing academic topics.

Despite the existence of research evidence suggesting negative attitudes of students towards the educational use of Facebook- students prefer to use it for the sake of social networking, which is the primary goal of the platform (Madge et al., 2009; Selwyn, 2009) -the lack of pedagogical experiences resulting from practical instructional activities on Facebook may be a factor in understanding these less positive views towards using Facebook as an educational environment (Hew, 2011). Yet, there is an array of research that has noted that students are keen on supporting their learning by employing social 
networking websites and generally possess positive attitudes towards the educational use of Facebook (Çoklar, 2012; Fewkes \& McCabe, 2012; Kirschner \& Karpinski, 2010). Overall, the available literature presents contradictory findings regarding students' perceptions of using Facebook as an instructional tool. That is to say, the fact that there is a lack of studies that specifically focus on students' reactions to their use of Facebook for formal learning purposes (Manca \& Ranieri, 2013) provides us with a challenge to systematically consider the variables describing students' perceptions of and experiences with using Facebook for their learning. Thus, further studies examining these factors are needed.

According to C. M. Wang (2012), instructional design is one of the most critical factors that influence students' use of Facebook as a learning tool. The results of Manca and Ranieri's (2013) literature review on the educational uses of Facebook suggest that the prevalent pedagogies of teachers and students possibly inhibit the benefits of using Facebook as a learning environment. The authors, therefore, stress the importance of using Facebook with contemporary instructional approaches that emphasise active student participation, the teacher role as facilitator rather than content provider, and the provision of multiple perspectives to students. McCarthy (2013) underscored a similar argument by stating that "pedagogical frameworks, informed by learner-centered principles, and sensitive to learning context, need to be considered" ( $p .340$ ) when designing instruction on Facebook. Contrary to traditional distance education systems, Facebook's features, such as a participatory culture, shared knowledge, and social communication, support the incorporation of a constructivist learning paradigm, which views learning as an interactive and authentic process where learners are responsible for their learning and are guided by the teacher (McCarthy, 2013; Rovai, 2004). Thus, Facebook`s implementation into learning settings may enhance learners' interaction and participation as a result of motivation and the novelty effect of technology-enriched instruction.

Within the current study prospective teachers not only designed and implemented instruction based on constructivist methods such as case-based learning, but they also experienced how novel technology and pedagogy were interrelated. Such authentic tasks and experiences may help prospective teachers to effectively integrate novel technology and innovative pedagogies into their professions and engender positive attitudes towards emerging technologies and instructional approaches in their disciplines. The purpose of this research was to explore a group of pre-service teachers' reflections on designing and implementing instruction on Facebook based on a constructivist learning paradigm.

\section{Method}

\section{Context}

The study took place in Teaching Methods II, a required 3-credit hours course open only to majors in Computer Education and Instructional Technology (CEIT), offered in a leading state university in Ankara, Turkey. This course emphasises the theory, research, and practice related to the application of four basic constructivist methods (case-based, problem-based, project-based, and collaborative learning) in online learning environments. The course had both theoretical and lab sessions, each of which took 2 hours in a week. As part of the theoretical sessions, the students were assigned texts and had lectures on teaching methods. During lab sessions, the students worked in small groups and engaged in several learning activities designed to help them apply what they learned in class to practical teaching-learning situations. Each group was to submit a final project related to designing and implementing an online instructional sequence based on a teaching method. The final project constituted $40 \%$ of the students' final course grade. Additionally, as part of the final project, participants were asked to write a reflection paper regarding their online teaching experiences. The study discussed in this paper focused on examining the reflections of pre-service teachers who collaboratively designed and implemented an instruction on Facebook.

\section{Participants}

Sixty-eight third-year prospective teachers enrolled in the course during the 2012-2013 spring semester. Among those, 14 groups, varying between 4 and 6 members in each group, were formed. The process was continued with 13 groups after the members of one group dropped the course. As the final project, each group was asked to determine a learning objective, design an instructional sequence according to the assigned method specific to that objective, and implement the instruction through an online environment 
for three weeks. Seven of the 13 groups preferred to use Facebook as the online teaching platform. Hence, the potential participants of the current study were the members of the seven groups $(n=33)$ who were asked to reflect on their teaching through Facebook. However, the number of the final participants contained 25 prospective teachers in addition to those who did not provide reflections $(n=6)$ or withdrew from the project submission $(n=2)$. Although these prospective teachers actively use Facebook for social networking purposes, at the time of the study they did not have any prior teaching experience on Facebook. Additionally, they had utilised the platform only to receive announcements in their previous two courses.

\section{Procedures}

The planning and implementation of the online instruction consisted of 14 weeks. In the first week, students were provided with an orientation on what they were supposed to do in line with the course context. At the fourth week, learners were asked to decide on a specific instructional method, subject matter, and learning objective for the final project, and come up with a tentative lesson plan. The following four weeks were devoted to determining the potential online students, learning outcomes, and media through which the instructional method would be implemented. Additionally, groups organised content, developed guidelines for their learners, and decided on the evaluation tools such as rubrics and interviews.

Seven groups of prospective teachers who decided to use Facebook for their instruction got in touch with their students in the ninth week and provided them with guidelines on the process and details of the project. The online students in the project consisted of freshman, junior, and senior students at the CEIT department of the two state universities in central Anatolia, Turkey. The collaboration between these two institutions was attained via the first researcher of the current study. The online students were allocated into groups in accordance with the selected topics and perceived learning outcomes. Thus, each group was assigned 10-12 students. Due to communication problems between the prospective teachers and online students at one of the institutions, the number of students in two groups was not adequate to pursue the study. Therefore, these students were replaced with other students enrolled at the same institution. Following the allocation of the online students, groups of prospective teachers created pages on Facebook and uploaded course materials such as instructional videos, presentations, pictures. By the 10th week, the Facebook course pages were complete, students were enrolled to the site, and provided with an orientation as an icebreaking activity. The actual online instruction was conducted between the 11 th and 14th weeks of the semester. The list of groups, targeted topics, and instructional methods are shown in Table 1 below.

Table 1

Groups, selected topics, and implemented instructional methods

\begin{tabular}{lll}
\hline Group & Topic & Method \\
\hline 1 & Classroom Management & Case-based learning \\
2 & Using Tablet PC in the Classroom & Case-based learning \\
3 & The New Primary Education System in Turkey & Case-based learning \\
4 & Using Web 2.0 in the Classroom & Case-based learning \\
5 & Constructivist Teaching Methods & Collaborative learning \\
6 & Introduction to HTML & Project-based learning \\
7 & Classroom Management & Case-based learning \\
\hline
\end{tabular}

While designing pedagogic activities according to different instructional methods by paying attention to their specific features and requirements, participants, in general, followed a similar framework. This framework included activities such as directing the attention of the students to the basic instructional unit, explaining their responsibilities to meet the assignments, guiding them in terms of the resources they may need to use to complete their course tasks, and facilitating the interactions and moderating the discussions of the students via prompt questions. Depending on the specific instructional method, the online learners were asked to either propose solutions to the cases or submit a small project on individual or group basis. To illustrate, groups utilising case-based learning generated discussions through the cases (e.g., class management) where students criticised opponents' views and decided on the solutions on a group and individual basis. The group studying with project-based learning initially provided examples on how to use HTML codes and then asked their learners to determine a project topic through which they would 
develop a website in groups of two. Later, group members explained each step of the project process and asked the learners to submit group reports on what had been done for each project step. The learners were also encouraged to share the codes through Facebook and receive feedback from the other groups. All learner groups submitted (their) overall project reports and the websites they developed in this period. The group studying with collaborative learning formed learner groups with three people and asked them first to discuss the pros and cons of constructivist teaching methods and then come up with a brief instructional design template. At the end, the learner groups generated a final report informed by suggestions from the other groups received through Facebook. The final report was also published on Facebook.

By the end of the third week of the instruction, each group of prospective teachers carried out a mixed method evaluation process using product and process assessment tools. The final project reports of the groups and prospective teachers' reflections on their instructional experiences were submitted through an online environment on the last (15th) week of the semester.

\section{Qualitative data: Prospective teachers' reflective papers on their teaching experiences}

Reflection is seen as a critical tool for advanced thinking skills such as problem-solving, critical analysis, synthesising, determining patterns, and evaluation. Since learning is a metacognitive act, learners should delve into what they have been exposed to in order to realise what they have acquired during the learning process. Thus, learners should be provided with the opportunity of reflecting on what they learned and how well they succeeded. This research aimed to explore the reflections of prospective teachers who designed and implemented instruction focusing on a specific method on Facebook. The participants were experienced in writing reflections, which is also the part of the Teaching Methods 2 course content. The student teachers were not provided with a structured format to generate their reflections. Instead, they utilised some guiding questions in the reflection examples they were provided within the course. Hence, the participants had the chance to organise their reflections in a cohesive and natural way. Examples of the guiding questions are as follows: (a) How did this specific learning activity contribute to your academic development? (b) How can you relate your overall prior learning experiences to the ones you have gained in this online teaching project?

\section{Data analysis}

The data gathered were analysed through thematic analysis where the epistemological aim is to give voice to the participants, to unravel the reality of the prospective teacher experience by identifying the patterns of meaning in their accounts (Braun \& Clarke, 2006). The methodology of thematic analysis in this study included the six-stage process recommended by Braun and Clarke (2006), where the entire data set was scanned various times, with the subsequent analysis involving familiarisation, generating codes and reviewing codes, searching for themes, and reviewing themes. The first of the three criteria for the review stage was to ensure that all the coded extracts for a theme were coherent. If they were not, the whole process of coding and identifying themes was carried out again. The second criterion is the distinctiveness of each of the main themes and involves being capable of articulating what the essence of each is. Lastly, the coded extracts that contributed to a theme were checked for internal consistency. After a considerable amount of recursive analysis, the main themes and their sub-themes were defined and named. In order to ensure the reliability of the collected data, using a coding scheme, an expert coded 112 data randomly selected among participants' reflections (327 in total) on their teaching via Facebook. The Kappa value was $0.74(p=0.00)$.

\section{Results}

This section is devoted to explanations on the main themes and sub-themes and examples from the prospective teachers' points of view regarding various aspects of online teaching within the current study. The six main themes, determined as a result of content analysis, are project design, applying instructional methods online, factors influencing effective teaching on Facebook, motivational issues, challenging issues, and future actions. The sub-themes related to each main theme (see Table 2) mentioned above are also provided and elaborated on. 
Table 2

Themes and sub-themes

\begin{tabular}{ll}
\hline Themes & Sub-themes \\
\hline Project design & 1. Rationale for choosing Facebook \\
& 2. Design of the instruction \\
Applying instructional methods online & 1. Opportunity to apply what they have learned \\
& 2. Online teaching experience \\
Factors influencing effective teaching & 1. Orientation and monitoring \\
on Facebook & 2. Use of language \\
& 3. Authentic content \\
Motivational issues & 1. Effective use of Facebook as instructional media \\
& 2. Effective communication and interaction within the \\
& project group \\
Challenging issues & 1. Enhancing interaction on Facebook \\
& 2. Limiting features of Facebook \\
& 3. Involvement in the project work \\
& 1. The selection of the learning environment \\
Future actions & 2. The enrichment of the learning environment \\
\end{tabular}

\section{Project design}

The project design theme includes two sub-themes: rationale for choosing Facebook and design of the instruction. Among many reasons for preferring Facebook platform, the participating prospective teachers noted their familiarity with Facebook, underlined its effectiveness in drawing learners' attention, and emphasised its facilitative role in their being able to follow the user activities and communicating via the online chat feature. Participants also pointed out that Facebook enables instant feedback, which increases the interaction significantly. For example, one participant said:

Facebook enables online chat feature and is easy to use with immediate feedback, and these are important to both us and the target audience. Besides, whenever an announcement or a discussion is created in the Facebook group, it automatically appears on the wall, so both students and we will be able to keep track of the course events by viewing the posts on the wall. (P21)

Concerning the design of the instruction, participants indicated that they considered the features of the instructional method, the implications of the constructivist theory underlying the method, and the characteristics of the target audience when designing the instruction. Correspondingly, one of the participants stated that:

The environment where we would use the method should have the specifications required by the constructivist approach. It should have been a design that ensures active student participation and interaction among students. As assessment would be not just for the outcome but also for the process, it was necessary to follow the activities of the students. (P11)

The prospective teachers also pointed out that they utilised audiovisual materials to draw the students' attention and tried to relate the content to real life. These prospective teachers further mentioned that they used supportive strategies (i.e., guiding questions) to help students to complete their tasks.

\section{Applying instructional methods online}

The two sub-themes concerning the contribution of teaching through Facebook to the prospective teachers' professional backgrounds are opportunity to apply what they have learned and online teaching experience. As for the first sub-theme, participants stated that their knowledge of how and which methods should be used in which learning environment were reinforced. They pointed out that they had the opportunity to apply what they have learned in theory, and thus, they learned the limitations, the positive and negative aspects, and implementation of teaching methods. One prospective teacher expressed the following views: 
In our face-to-face course, we learned how to write a case and what procedures to follow in the implementation phase of the case method. Throughout the online teaching process, we had the opportunity to practise what we have learned. This project allowed us to make a connection between theory and practice. (P14)

Regarding the second sub-theme, the prospective teachers indicated that they had gained experience in teaching through online environments. They further declared that they had improved in implementing some sophisticated instructional methods capable of providing learners with advanced learning outcomes on the Internet and developed an overview for integrating Facebook in education. One participant's views on this subject are as follows:

Thanks to this project, I have met the media (Facebook) I will use in my teaching career. I noticed the importance of giving information to students in different media. How the students behave outside the classroom allowed me to see what they are doing in the online learning process. I have learned important issues about how I should manage students in distance education and what kind of instructions I should give. (P5)

\section{Factors influencing effective teaching on Facebook}

Three sub-themes were identified in terms of the prospective teachers' perceptions related to the factors influencing the effective teaching on Facebook. These sub-themes are orientation and monitoring, use of language, and authentic content. The participating prospective teachers mostly emphasised that orientation and monitoring the process were the most influential factors in the effectiveness of teaching on Facebook. They pointed out that while teaching online, the critical factors are giving clear instructions and feedback to the learners, intervening and directing the discussions, and monitoring the teaching program continually. One participant stated:

When we added members to the learning environment on Facebook, they were asking us questions as they didn't know what to do. But then, they did not need to ask any questions as we gave clear and detailed instructions throughout the process. I realised that in order to pursue an effective online instruction, the teacher should be continuously present in the environment and give instructions to sustain the learners' well-being. (P6)

Additionally, prospective teachers underlined the use of informal language on Facebook to draw student interest. One participant said:

If there is a serious atmosphere in the environment, the students move away from the course due to boredom. That's why behaving like in a real class is much more effective. I realised, like in a normal class, uttering friendly sentences and making jokes helped to create an environment that supported the active participation of the online learners in the Facebook debates. (P11)

The participants also observed that relating the learning environment to daily life attracted the attention and increased the participation of students. One participant's opinion is as follows:

The topic we chose was related to using tablets in education. Because tablets are very upto-date tools, the topic received the attention of the participants, and they gained knowledge due to its promising effect on their future professions. (P23)

\section{Motivational issues}

The factors driving the pre-service teachers' motivation to teach on Facebook were determined within two sub-themes, which are effective use of Facebook as instructional media and effective communication and interaction within the project group. Initially, participants who claimed to use Facebook effectively explained their accomplishments in terms of their familiarity with the medium and their efforts in tracking online activities and follow-up discussions of students on Facebook. One participant stated: 
I see myself successful in examining Facebook discussions and providing feedback to the students' comments. I think I was competent in tracking who participated in the discussions and who did not, so I was able to incite passive students to share their ideas more. (P10)

Almost all the prospective teachers also stated that using Facebook as a teaching environment was quite enjoyable owing to its interactive nature. One participant said:

I liked using Facebook as a learning medium, starting a virtual group on Facebook, participation of other classmates in the discussion, and managing the discussions among the students. When we saw someone participating in the discussion, we enjoyed it. (P22)

A large part of the prospective teachers indicated that they had fun and experienced satisfaction due to the effective communication among team members during the project period, the fulfillment of the responsibilities of the members, and active participation in the meetings of the group. One participant expressed the following ideas:

I believe that working together as a group is critical to be successful. We were able to accomplish the project without having any problems. Getting well within the group, delving into ideas of other people, and working in harmony was the most enjoyable part of the study. (P3)

\section{Challenging issues}

The participating prospective teachers' perceptions of the challenges they faced throughout the project were determined in three sub-themes as enhancing interaction on Facebook, limiting features of Facebook, and involvement in the project work. Admittedly, the main challenges experienced by the prospective teachers were drawing the attention of online students, ensuring their participation in the discussions, and providing feedback to them. For example, one prospective teacher underlined the difficulty of receiving the students' full attention and involvement by saying:

It is hard to do training on Facebook, because attracting students to Facebook and managing them on Facebook is difficult. Though we directed everyone, only four people effectively participated in the activities carried out. It took a lot longer to wait for our students' active participation than to complete our project. To draw the attention of my prospective students when I become a teacher seems to be a significant problem. (P15)

While some of the prospective teachers followed the discussions all the time and wrote replies to improve student participation, some stated that they could not deal with this problem. In fact, very few prospective teachers expressed their opinions on the subject. Similarly, another prospective teacher mentioned the difficulty of providing feedback to the students in Facebook and explained that this type of problem might have existed due to their being inexperienced in this regard.

As for the limiting features of Facebook sub-theme, some of the prospective teachers argued that moderating and tracking the discussions on Facebook was difficult, as the online discussions flew too fast and the system did not support threaded discussions. One of the participants stated:

The discussion section of Facebook had some limitations. For instance, when a student replied to a posting in the discussion forum, she had to explicitly mention which posting that her response was referring to, because the posts were not organised in threads. This made the tracking of the discussions complicated for both us and the students. (P16)

In response to the problem of tracking discussions on Facebook, some of the groups applied the strategy of one of the group members posting a question to initiate a discussion and then asking the students to share their ideas by replying to the particular posting he/she had just created. These groups, therefore, were able to monitor the development of the discussions. 
Other challenges due to the limiting features of Facebook were the lack of control over the visibility of the messages on the wall and the organisation of the course resources. Two participants' views on this subject are as follows:

Posts were restricted in length, so when the students wrote a long message only a small amount appeared on the page and they had to click on "See more" to see the rest. Besides, not all the responses under a post appeared on the wall. Therefore, the students had to click on "View x more comments", which in some cases was missed or ignored by the students. (P7)

We put all the related resources on the "Files" section but the system did not allow us to organise them into folders. Therefore, students became confused about which resources they needed to usefor which tasks. After the instructor's guidance, we provided the students with explanations about the useful resources for their tasks, yet these explanations easily became invisible due to the fast flow of the discussions. (P15)

Concerning the third sub-theme, some teacher candidates indicated that they experienced problems in group work due to the lack of communication and coordination among the group members. To overcome the difficulties related to the group work, one participant stated that they established a group on Facebook:

We solved this communication problem by forming a group on Facebook. Thus, we eliminated the problems of undelivered emails, and not seeing others'emails. Everyone in the group could easily follow one another and reply to the group messages. (P14)

\section{Future actions}

Two of the sub-themes that were identified about what the prospective teachers would do if they took part in a similar project were the selection of the learning environment and the enrichment of the learning environment. Regarding the first sub-theme, two prospective teachers pointed out that they would use another environment rather than Facebook and would prefer to develop their own online environment. One of these participants said:

Facebook causes distractions, and to provide feedback to the participants' solutions is quite difficult. When confronted with the process of making a similar project, I would design it myself. Here, we used a ready-made environment. I would use Dreamweaver or some other kind of web tool to develop a new learning environment that would better meet my project goals. (P7)

With respect to the second sub-theme, the participants stated that they would exploit multimedia elements for the sake of a more motivating instructional sequence, provide brief information while presenting the content, and utilise synchronous communication to enhance interaction. Another participant said s/he would design a more attractive Facebook environment and guide students with more explicit directions. S/he stated:

I would design a Facebook environment that would attract the students' attention. For instance, the different media formats could be integrated into the Facebook messages, so I could present the cases in video format in order to make them more vivid. I would get experts' opinions on the questions that we used to guide students' online discussions so as to make them more vigorous and explicit. (P23)

Other participants said they would give the content in the form of a summary in order not to bore the students and to highlight important points. One of them emphasised that:

Rather than giving the resources directly, I would strain all the resources in the form of summary information. It may be boring to read long documents but it would be better if the information were in a summary format. (P6) 
In addition, another participant mentioned the importance of discussion on Facebook and added that in order to increase interaction, synchronous communication as well as asynchronous communication could be exploited:

The most important part was online discussion. I would try to increase the interaction at this point. For example, sessions could be organised for asynchronous communication as well as synchronous mode. Maybe I would give the cases to two different groups and make them discuss to come up with a shared solution. (P12)

\section{Discussion and conclusion}

The present study was designed to determine the reflections of a group of prospective teachers who were assigned to design and conduct instruction through Facebook as a social networking site. The participants were also asked to construct the instructional design using a specific teaching method. As one of the more significant findings to emerge from this study, the participants explained the rationale for favouring Facebook as a learning mediumby their familiarity with Facebook and their belief in its supportive role in creating and sustaining interactivity among the users. Although the participants did not have any educational experience with Facebook, their positive perception of the educational potential of the platform to enhance interactive learning is both notable and promising in terms of the successful implementation of social networking sites in educational settings in the future. This finding suggests that in general the participants' own experiences in using Facebook for social networking purposes give them confidence in using the tool for teaching and sustaining learner interactivity through Facebook. As asserted by Manca and Ranieri (2013), being familiar with the features of Facebook potentially reduces the risk of technological frustration on the part of the users and may accelerate the interest in using this tool for educational purposes. In fact, most of the prospective teachers kept their positive point of view towards the educational use of Facebook at the end of the instructional activities held in the research process. All but two of the participants stated that if they were involved in a similar project, they would use the Facebook platform. This finding implies that nearly all of the participants perceived Facebook as a promising and effective learning environment, and they do not have any concerns about using Facebook as a teaching medium in their future professions. In line with the research evidence and the beliefs underlining its positive role in overcoming the interaction and social networking problems of traditional distance education systems, the incorporation of Facebook into the curriculum will increase enormously in the near future (DiVall \& Kirvin, 2012; Estus, 2010; Heiberger \& Harper, 2008; McCarthy, 2013). Hence, the positive perceptions of the prospective teachers of the educational use of Facebook can be an opportunity for incorporating this tool into their target professional environments.

One of the additional conclusions that can be drawn from the present study is that the prospective teachers perceived the design of instruction based on a constructivist method as one of the critical success factors in the process of using Facebook as an instructional tool. This finding is consistent with the arguments stated by Manca and Ranieri (2013) and McCarthy (2013). These researchers argued that in order to get benefit from Facebook as a learning environment, the instruction should be designed with a philosophy promoting the latest learning paradigms, such as learner centeredness, collaboration, and inquiry-based instruction. Thus, exploiting Facebook requires designing pedagogically sound learning methods and incorporating these methods into Facebook. Therefore, the participants' declaration about the improvement in their overall knowledge of contemporary online instructional methods should be considered as a major finding of the current study. While designing their instruction through Facebook, the participants not only aimed at aligning it with the constructivist learning paradigm but they also considered Facebook as a convenient medium to reflect the pedagogic features set by the constructivist paradigm.

In order to ensure the effectiveness of the instruction on Facebook, the prospective teachers believe that students need to be guided through the features of the medium and that teachers need to keep in touch with the students' online activities. The participants also pointed out that using authentic tasks and an informal style of communication improved learner engagement and motivation in the Facebook learning environment. These findings are important as there has been lack of research on the critical factors that can influence the success of Facebook as an educational tool (Kabilan et al., 2010; Manca \& Ranieri, 2013). The participants of the current study examined these critical factors through authentic application. Although providing such authentic experiences is very supportive for prospective teachers, student 
teaching experiences in Turkish teacher education settings are scheduled at the last year of the programs and contextualised for only in-class teaching mode. The rapid spread of online learning environments, however, requires providing the prospective teachers with the skills to plan and implement instruction in online professional situations. The participants of the present study pointed out that the online teaching project contributed to their understanding of how face-to-face instructional methods can be effectively implemented online and how Facebook can be exploited to serve as an interactive online learning platform. Moreover, most of the participants stated that they had the chance to practise their theoretical knowledge of instructional philosophy in the process of course design and implementation on Facebook. This specific result also indicates that teaching on Facebook contributed to the prospective teachers' overall professional development in terms of synthesising various aspects of online instructional design, such as instructional principles, classroom management, and distance education technology. Admittedly, prospective teachers who have been equipped with online teaching skills and experiences will presumably be more capable of integrating novel technology and solving learning problems in real-life teaching settings compared to those who have not had the same pre-service training.

Another significant finding to emerge from this study is the overlap between the participating prospective teachers' perceptions of their successes and satisfaction within the whole period of the study. The participants not only perceived themselves as successful in working in collaboration, and conducting teaching on Facebook, but they also mentioned their satisfaction in pursuing these activities in the study. This finding implies that prior experiences of prospective teachers with using Facebook for social networking purposes and collaborative group work might have positively affected their motivation and the success of the project. As another major finding of the current study, one of the project groups utilised Facebook to coordinate communication and facilitate negotiation among group members. Correspondingly, previous research has pointed out that Facebook provides learners with opportunities to enhance interaction and encourage collaboration for pedagogical purposes (Dalsgaard, 2008; Huijser, 2008; Pempek et al., 2009; Rutherford, 2009; Schwartz, 2009; Wiberg, 2007; Yu et al., 2010). Undoubtedly, all these views should be evidenced via empirical research. For instance, the dynamics of group work conducted through Facebook can be investigated in terms of both positive and negative factors affecting the learning outcomes; thus new insights can be obtained for designing Facebook-based learning environments for collaborative group work.

In addition to the various advantages of instructional design and implementation through Facebook, some challenges arising during the project were also reported by the participants. For example, many participants underlined the difficulty of attaining the attention and engagement of online learners. Similar outcomes have been reported by previous research as well (English \& Duncan-Howell, 2008; Kop et al., 2011; Selwyn, 2009), and the educational potential of Facebook has been questioned by some academics, who are still in doubt as to whether Facebook should be considered as a learning environment (Kabilan et al., 2010; Wise et al., 2011). In the current study, very few of the participants tangentially explained how they tried to overcome the motivation and engagement problems of the online learners in their projects. Hence, the results suggest that the participants could not provide effective strategies to solve these problems. Nevertheless, this study has also shown that many prospective teachers learned from their failures and gained significant learning experiences in attaining learner engagement within their online teaching. The participants listed a number of strategies that they would implement to enrich the learning environment and strengthen communication with online students. These strategies included emphasising critical points throughout the content, supporting the content with multimedia, providing crystal-clear guiding questions, utilising both synchronous and asynchronous tools, and regularly interacting with students. A considerable amount of literature has been published on the positive effect of these strategies within online learning environments (Fich \& Hiltz, 2003; Rovai, 2004; Swan, 2001; H. C. Wang \& Chiu, 2011). Participants' reflections on these critical strategies as a result of a short-term online learning experience should be considered as a valuable learning outcome.

Another challenge reported in the results section is related to the participants' little or no control over the design of the Facebook interface. As argued by Wise et al. (2011), lack of control over the appearance and structure of pages on Facebook restricts an instructor's contribution to the design of the instruction to improve students' engagement and learning, and thus impedes the pedagogical affordances of Facebook. Similarly, Arola (2010) expressed the view that template-driven design in Facebook discourages both students and instructors from creating designs and limits the user's actions to the predetermined options set by the developers of the tool. In fact, many Web 2.0 tools, including Facebook, can assist those who 
do not have the necessary technical skills to create their own websites. However, not having a choice of design on Facebook can diminish its potential as a learning tool, so we, as instructional designers, should develop a deeper understanding of how Facebook or other social networking tools can better serve our instructional goals.

To sum up, the current study aimed at exploring the reflections of a group of prospective teachers who designed and conducted instruction on Facebook by implementing a learner-centred teaching method. A growing interest has been observed on the instructional use of Facebook throughout the relevant literature; nevertheless, much of the research up to now has focused on the general educational use of Facebook rather than users' instructional experiences and reflections. Furthermore, the experiences, perceptions, and attitudes of prospective teachers regarding the educational potential of Facebook tend to be neglected. This study points out that participating prospective teachers possess a positive attitude towards the educational use of Facebook and are eager to utilise the platform in their future professions. Moreover, testing the efficiency of constructivist learning methods through Facebook is another valuable asset of the design of the current study, through which prospective teachers experienced the kind of problems that may occur and considered how to handle these problems while implementing constructivist methods. Thus, the results of this study will provide insights and information on how Facebook can be utilised for teacher education purposes. It is recommended that researchers and teacher trainers design further studies and projects to provide instructional experiences for prospective teachers in various professional contexts.

\section{Limitations of the study}

Finally, a number of important limitations need to be considered. The most important limitation lies in the fact that reflective accounts of the prospective teachers should be regarded as a valuable source. Having said that, the data could have been triangulated through participant interviews and/or products could have been developed throughout the study for the sake of trustworthiness of the study. Furthermore, the prospective teachers were provided with a three-week time period for online teaching through Facebook, which may not be sufficient to fully and efficiently implement the project. This is a very short period of time, especially because the teaching methods that prospective teachers were asked to implement typically require a much longer time frame. In this sense, further studies should delve into including longer applications of these methods.

Another important caveat of the study is that previous familiarity of the participants with the Facebook environment might produce bias towards Facebook. This bias might have arisen from participants' frequent use of Facebook in their daily lives and their beliefs in its ease-of-use and potential educational efficacy. Thus, if possible, further studies are highly recommended to include participants with less or no Facebook experience prior to exposure in order to examine the factors affecting the perceptions of participants having various experience levels with Facebook.

\section{References}

Alloway, T. P., \& Alloway, R. G. (2012). The impact of engagement with social networking. Computers in Human Behavior, 28(5), 1748-1754.

Arola, K. L. (2010). The design of Web 2.0: The rise of the template, the fall of design. Computers and Composition, 27, 4-14.

Bosch, T. (2009). Using online social networking for teaching and learning: Facebook use at the University of Cape Town. Communicatio: South African Journal for Communication Theory and Research, 35(2), 185-200.

Braun, V., \& Clarke, V. (2006).Using thematic analysis in psychology. Qualitative Research in Psychology, 3, 77-101.

Çoklar, A. N. (2012). Evaluations of students on Facebook as an educational environment. Turkish Online Journal of Qualitative Inquiry, 3(2), 42-53.

Dalsgaard, C. (2008). Social networking sites: Transparency in online education. Paper presented at EUNIS Congress, University of Aarhus, Denmark.

DiVall, M. V., \& Kirwin, J. L. (2012). Using Facebook to facilitate course-related discussion between students and faculty members. American Journal of Pharmaceutical Education, 76(2), 1-5. 
English, R., \& Duncan-Howell, J. (2008). Facebook@ goes to college: Using social networking tools to support students undertaking teaching practicum. MERLOT Journal of Online Learning and Teaching, 4, 596-601.

Estus, E. L. (2010). Using Facebook within a geriatric pharmacotherapy course. American Journal of Pharmaceutical Education, 74(8), 1-5.

Fewkes, A. M., \& McCabe, M. (2012). Facebook: Learning tool or distraction? Journal of Digital Learning in Teacher Education, 28(3), 92-98.

Fich, R. B., \& Hiltz, S. R. (2003). Mediators of the effectiveness of online courses. IEEE Transaction on Professional Communication, 46(4), 298-312.

Greenhow, C. (2011). Online social networks and learning. On the Horizon, 19(1), 4-12.

Heiberger, G., \& Harper, R. (2008). Have you Facebooked Astin lately? Using technology to increase student involvement. In R. Junco \& D. M. Timm (Eds.), Using emerging technologies to enhance student engagement. New Directions for Student Services, Issue 124 (pp. 19-35). San Francisco, CA: Jossey-Bass.

Hew, K. F. (2011). Students' and teachers' use of Facebook. Computers in Human Behavior,27(2), 662676.

Hewitt, A., \& Forte, A. (2006). Crossing boundaries: Identity management and student/faculty relationships on the Facebook. Paper presented at Computer-Supported Cooperative Work, Banff, Alberta, Canada.

Huijser, H. (2008). Exploring the educational potential of social networking sites: The fine line between exploiting opportunities and unwelcome imposition. Studies in Learning, Evaluation, Innovation and Development, 5(3), 45-54.

Kabilan, M. K., Ahmad, N., \& Abidin, M. J. Z. (2010). Facebook: an online environment for learning of English in institutions of higher education? The Internet and Higher Education, 13(4), 179-187.

Kirschner, P. A., \& Karpinski, A. C. (2010). Facebook and academic performance. Computers in Human Behavior, 26, 1237-1245.

Kop, R., Fournier, H., \& Mak, J. S. F. (2011). A pedagogy of abundance or a pedagogy to support human beings? Participant support on massive open online courses. The International Review of Research in Open and Distance Learning, 12(7), 74-93.

Lin, P., Hou, H., Wang, S., \& Chang, K. (2013). Analyzing knowledge dimensions and cognitive process of a project-based online discussion instructional activity using Facebook in an adult and continuing education course. Computers \& Education, 60, 110-121.

Madge, C., Meek, J., Wellens, J., \& Hooley, T. (2009). Facebook, social integration and informal learning at university: 'It is more for socialising and talking to friends about work than for actually doing work'. Learning, Media \& Technology, 34(2), 141-155.

Manca, S., \& Ranieri, M. (2013). Is it a tool suitable for learning? A critical review of the literature on Facebook as a technology-enhanced learning environment. Journal of Computer Assisted Learning, 29(6), 487-504.

McCarthy, J. (2009). Utilising Facebook: Immersing Generation-Y students into first year university.ergo, 1(2), 39-49.

McCarthy, J. (2013). Learning in Facebook: First year tertiary student reflections from 2008 to 2011. Australasian Journal of Educational Technology, 29, 337-356. Retrieved from http://www.ascilite.org.au/ajet/submission/index.php/AJET/index

Pempek, T. A., Yermolayeva, Y. A., \& Calvert, S. L. (2009). College students' social networking experiences on Facebook. Journal of Applied Developmental Psychology, 30(3), 227-238.

Rovai, A. P. (2004). A constructivist approach to online college learning. The Internet and Higher Education, 7, 79-93.

Rutherford, C. (2009). Facebook as a form of informal teacher professional development. Paper presented at the Annual Meeting of the Canadian Society for the Study of Education. Ottawa, Canada. Retrieved from http://ocs.sfu.ca/fedcan/index.php/csse2009/csse2009/paper/viewFile/1932/596

Schwartz, H. L. (2009, September 28). Facebook: The new classroom commons? The Chronicle of Higher Education, 56(6), B12-B13. Retrieved from http://chronicle.com/article/Facebook-The-NewClassroom/48575/

Selwyn, N. (2009). Faceworking: Exploring students' education-related use of Facebook. Learning, Media and Technology, 34, 157-174.

Swan, K. (2001). Virtual interaction: Design factors affecting student satisfaction and perceived learning in asynchronous online courses. Distance Education, 22, 306-331.doi:10.1080/0158791010220208 
Wang, C.-M. (2012). Using Facebook for cross-cultural collaboration: The experience of students from Taiwan. Educational Media International, 49(1), 63-76.

Wang, H. C., \& Chiu, Y. F. (2011). Assessing e-learning 2.0 system success. Computers \& Education, $57,1790-1800$.

Wiberg, M. (2007). Netlearning and learning through networks. Educational Technology \& Society, 10(4), 49-61.

Wise, L. Z., Skues, J., \& Williams, B. (2011). Facebook in higher education promotes social but not academic engagement. In G. Williams, P. Statham, N. Brown, \& B. Cleland (Eds.), Changing Demands, Changing Directions. Proceedings ascilite 2011 (pp.1332-1342). Hobart: University of Tasmania. Retrieved from http://ascilite.org/conference/past-proceedings/

Yu, A. Y., Tian, S. W., Vogel, D., \& Kwok, R. C. (2010). Can learning be virtually boosted? An investigation of online social networking impacts. Computers \& Education, 55, 1494-1503.

Corresponding author: Yasemin Demiraslan Çevik, yasminey13@gmail.com

Australasian Journal of Educational Technology (C) 2014.

Please cite as: Demiraslan Çevik, Y., Çelik, S., \& Haşlaman, T. (2014). Teacher training through social networking platforms: A case study on Facebook. Australasian Journal of Educational Technology, 30(6), 714-727. 